\title{
Examination of the Relationship between Coach-Athlete Communication Levels and Perceived Motivational Climate for Volleyball Players ${ }^{i}$
}

\author{
Kübra Seden Avcı ${ }^{1}$, Fatma Çepikkurtt ${ }^{1, *}$, Esen Kızıldağ Kale ${ }^{2}$ \\ ${ }^{1}$ Physical Education and Sport High School, Mersin University, Turkey \\ ${ }^{2}$ Physical Education and Sport High School, Nişantaşı University, Turkey
}

Copyright $\bigcirc 2018$ by authors, all rights reserved. Authors agree that this article remains permanently open access under the terms of the Creative Commons Attribution License 4.0 International License

\begin{abstract}
The aim of this study was to reveal the relationship between the athlete-coach relationship and the motivational climate created by the coach. In this study, relational survey model was used. The study sample included 96 female volleyball players who are active players at Turkey Women Volleyball 3rd League. "The Coach-Athlete Relationship Questionnaire" and "The Perceived Motivational Climate in Sports Scale" were used to collect the data. The data were examined by using descriptive statistics, Pearson Correlation Analysis and Canonical Correlation Analysis. Correlational analysis revealed that the perceived mastery motivational climate, in which role sharing in team, co-operation with teammates, and improvement are emphasized, were associated with experiencing higher levels of closeness, commitment and complementarity with coach. Also, according to canonical correlation results, the coach-athlete relationship and motivational climate data sets account for $13.32 \%$ of variance in the first canonical function. These findings indicate that three interpersonal construct of complementarity, closeness, and commitment are high for this volleyball group, and also they perceive their training and competition environment as mastery-oriented. These results support the only first hypothesis of research that the coach-athlete relationship is positively associated with the mastery-oriented motivational climate. In this context, it can be said that coach-athlete relationship may affect the motivations of athletes in team sports.
\end{abstract}

Keywords Coach-Athlete Relationship, Motivational Climate

\section{Introduction}

The most important people influencing athletes' experiences in sports are coaches. The relationship between the athlete and the coach has recently become one of the most interesting topics in the field of sports psychology [1]. The quality of the relationship established between the coach and athlete forms the basis of athletic training and successful coaching [2]. The coach-athlete relationship is expressed as a situation in which the feelings, thoughts and behavior of coaches and athletes are mutually and causally interconnected [3]. This definition emphasizes the dual nature of the coach-athlete relationship; the feelings, thoughts and behavior of the coach is both affected by and affect the feelings, thoughts and behavior of the athlete. This definition also promotes the belief that the coach-athlete relationship is multidimensional, and therefore the emotional, cognitive, and behavioral aspects of the relationship must be taken into account $[4,5]$.

In studies made in the field of sports psychology, models for describing the coach-athlete relationship have been presented $[3,6,7]$. One of these models is the 3-Cmodel (commitment-closeness-complementarity) introduced by Jowett et al. [8] based on a study by Kelly et al. (1983). The 3-C model describes three basic dimensions that define the coach-athlete relationship: commitment, closeness and complementarity. "Commitment" refers to devotion without reciprocation, the continuity of the relationship, the desire for the relationship, and positive intent. "Closeness" denotes emotional reciprocity and trust, fondness, and respect for another person [9] "Complementarity" describes the interactive process that promotes teamwork, mutual support, and cooperation [9] The concept of complementarity emphasizes working together in a friendly, sensitive and willing fashion to improve the performance of the coach and athlete (10). Co-orientation, or shared beliefs, interests, values, and goals, can only be achieved through open communication and includes discussions, dialogues, negotiations and decision-making 
processes. As shown in the model presented by Jowett, coach's and an athlete's thoughts of commitment, feelings of closeness, and complementarity behaviors are the major determinants that constitute the coach-athlete relationship all of which are mutually interdependent (11).

It has been suggested that the motivation for coaches to participate in training and competition is influenced by their organization and practices, behaviors, and how they communicate with their athletes $[11,12]$. Coaches can positively affect their athletes' abilities, beliefs and the pleasure they derive from sports, contributing to the development of competitiveness and gaining experience of mastery $[14,15]$. In addition, much as coaches contribute to the individual development and acquisition of positive life skills of their athletes [16], it is also possible that they may increase the stress and burnout that their athletes experience, even causing some athletes to quit sports altogether [13, 15].

Upon reviewing studies on the athlete-coach relationship, it has been found to be associated with such variables as personality factors [18], collective competence [19], passion [20], empathic accuracy and satisfaction [21] and psychological needs and well-being (22). One of the variables discussed in studies of the athlete-coach relationship is the motivational climate created by the coach and some studies have highlighted that perceptions of the quality of the coach- athlete relationship may influence athletes' motivational dispositions (23).

Motivational climate is a situational structure that reveals how the training environment and achievement evaluations (situational targets) created by the coach are perceived by athletes within the athletic environment [24, 25]. Motivational climate describes the situational nature of coaches' behavior in training and competitions, their reaction to success and failure, their competitive level, the formats of guidelines given, and the evaluations of key people. More explicitly, motivational climate describes how the athletic environment is perceived by athletes. According to Achievement Goal Theory (AGT), there are two different perceived motivational climates, the "mastery-oriented motivational climate" and "performance-oriented motivational climate". Mastery-oriented motivational climate concerns individual progress (i.e., current performance compared to previous performance), skill enhancement, the effort made, the contribution of each team member to the performance, team members' willingness to not only learn but also perform new tasks, and their support for each other. Performance-oriented motivational climate is characterized by a training environment involving comparison of team members' performances, competition between individuals, general evaluations, and social comparisons $[26,27,28,29,30]$. Additionally, once the athletes consider that their mistakes would be punished by their coach, they are classified according to their ability level by their coach and this environment subsequently promotes the intra-team member rivalry (31). According the AGT, there may be some complements of motivational climate (32). When motivational climate was perceived as higher level of task and lower level of ego involving features, athletes showed more positive behaviors and reported more positive moral attitudes. On the other hand, when motivational climate was at a lower level of task-and higher level of ego-involving features, athletes reported approval of amoral behaviour, less approval of respect for rules and officials, and lower commitment to continued participation in response to failure.

Among researchers who have studied the relationship between the coach-athlete relationship and motivation, Antonini-Philipe and Seiler [9] found that coaches tried to increase their athletes' motivation of the athletes by using interpersonal techniques, and that coaches who establish effective communication and provide social support facilitate the ability of their athletes to improve their performance and actually enjoy sports. According to Pensgaard and Roberts [33], enjoyment is very important in athletics and competition, and the level of enjoyment experienced in athletics is highly correlated with the attitudes and behaviors of coach. They stated that coaches who exhibit an acceptable and supportive attitude in training and competition and who create a mastery-oriented motivational climate increased the pleasure derived from sports and contributed to the improvement of performance. A study of Spanish handball players by Balaguer, Duda, Atienza, and Mayo [34] investigated the relationship between motivational climate and coach behaviors and found that the athletes who perceived a mastery-oriented motivational climate more intensely perceived their coaches as more supportive from a technical, tactical, and psychological standpoint. They also stated that these athletes regarded their coaches as "ideal" coaches. Olympiou, Jowett, and Duda [35] found a positive correlation between a mastery-oriented motivational climate and closeness, commitment, and complementarity in the coach-athlete relationship. On the other hand, they also revealed that in a performance-oriented motivational climate, trainers whose athletes who felt that their trainers punished them for mistakes, supported rivalry and did not treat all their athletes equally received lower scores for commitment, closeness and complementarity.

It was stated in a previous investigation (Adie \& Jowett, 2010) that a higher quality coach-athlete relationship closely related to mastery-approach goals and negatively to performance-avoidance goals. Besides, it also concluded that an athlete perceiving a good relationship with his/ her coach in terms of closeness, commitment and complementarity may be more possibbly to maintain approach goals in order to exhibit competence to $\mathrm{him} / \mathrm{herself}$ and to others while a poor relationship cause athlete to adopt avoidance goals in order to hide a lack of personal competence. Moreover, the results of their study 
revealed that the mastery-approach goals partially mediated the link between the coache-athlete relationship and intrinsic motivation (23).

According to the literature, a correlation exists between the coach-athlete relationship and the motivational climate, and athletes who have good relationships with their coaches perceive their training environments as more positive and supportive.

Based on the above explanations and previous research findings, this goal of this study was to reveal the relationship between the athlete-coach communication and the motivational climate created by the coach. In this context, answers to the following hypotheses were sought:

Hypothesis 1: The commitment, closeness, and complementarity subscale scores of the coach- athlete relationship inventory are positively associated with the mastery-oriented motivational climate.

Hypothesis 2: The commitment, closeness and complementarity subscale scores of the coach- athlete relationship inventory are negatively associated with the performance-oriented motivational climate.

\section{Materials and Methods}

\subsection{Model}

Because this study concerns the relationship between the coach-athlete relationship and the motivational climate created by the coach, it is a study in the relational survey model [36]. The correlational research model enables the determination of the relationship or the degree of the relationship between two or more variables [36].

\subsection{Study Group}

A total of 96 female volleyball players between the ages of 15 and $31\left(\mathrm{X}_{\text {age }}=19.97 \pm 4.48\right)$ who are active members of the 3rd League Women's Volleyball teams in Mersin, Adana, and Osmaniye, Turkey agreed to participate in this study. Since there is no minimum age limit in this league, the age range of participants varies from 15 to 31 . The average number of years that they had been participating in sports was $\mathrm{X}_{\mathrm{age}}=8.18 \pm 4.05$ years, while the average time spent working with the same coach was $\mathrm{X}_{\text {age }}=2.79 \pm 1.87$ years. The volleyball players participating in this study were high school $(\mathrm{n}=22 ; 22.92)$ or college students $(\mathrm{n}=74 ; \%$ 77.08), respectively.

\subsection{Data Collection Tools}

A personal information form, the Coach-Athlete Relationship Questionnaire and the Perceived Motivational Climate in Sports Scale were used for the volleyball players participating in this study.

"The Coach-Athlete Relationship Questionnaire (CART-Q)" was developed by Jowett and Ntoumanis [3] and adapted for Turkish by Altıntaş et al. [37]. The inventory has two forms for the athlete and the coach, each consisting of 11 items. In this study, the 'Athlete Form' was used to evaluate the relationship of the athlete with the coach. The questionnaire is composed of three sub-scales: Closeness (4 items), Commitment (3 items), and Complementarity (4 items), for a total of 11 items. The reliability coefficients calculated using Cronbach's Alpha for this study were .82 for the 'closeness' sub-scales; .59 for 'commitment', and .78 for 'complementarity'.

"The Perceived Motivational Climate in Sport Scale" was developed by Walling, Duda, and Chi [38] and adapted for Turkish by Toros [39]. The scale consists of 2 sub-scales, for the mastery-oriented and performance-oriented motivational climates, with a total of 21 items. In this study, the internal consistency coefficients calculated using Cronbach Alpha were .87 for the mastery-oriented motivational climate subscale and .69 for the performance-oriented motivational climate subscale.

\subsection{Assumptions}

This study is based on two fundamental assumptions. The first is that the sample taken for this study is assumed to possess all the properties of the entire population (of athletes) and is thus representative of the whole. The second assumption is that data obtained reflect the true and sincere responses of the participants to the survey.

\section{5. Analysis of Data}

Descriptive statistics and the Pearson Correlation Analysis technique were used to analyze the data. In addition, Canonical Correlation Analysis was applied in order to determine the relationship between sub-scales of the Coach-Athlete Relationship Inventory and the Perceived Motivational Climate in Sport Scale. Canonical Correlation Analysis is a multivariate analysis method that investigates the relationship between two sets of variables in data sets composed of multiple variables [40, 41]. The goal of Canonical Correlation Analysis is not to develop a model for variables but rather to reveal the relationship between variables [42].

\section{Results}

The mean and standard deviation values of the scores of the study participants for the Coach-Athlete Relationships Questionnaire and the Perceived Motivational Climate in Sport Scale are presented in Table 1. 
Table 1. Mean and standard deviation, skewness and kurtosis scores of the Coach-Athlete Relationships Questionnaire and Perceived Motivational Climate in Sport Scale scores

\begin{tabular}{|c|c|c|c|c|c|c|}
\hline Scales' sub-dimensions & $\mathbf{n}$ & $\begin{array}{c}\text { Response } \\
\text { Scale }\end{array}$ & Mean & S. D. & Skewness & Kurtosis \\
\hline Performance-oriented & 96 & $1-5$ & 3.09 & .52 & 1.14 & 1.06 \\
\hline Mastery-oriented & 96 & $1-5$ & 3.89 & .73 & .85 & .39 \\
\hline Complementarity & 96 & $1-7$ & 5.99 & 1.06 & 1.41 & 1.72 \\
\hline Commitment & 96 & $1-7$ & 6.42 & .93 & 1.15 & 1.27 \\
\hline Closeness & 96 & $1-7$ & 6.61 & .70 & 1.28 & 1.15 \\
\hline
\end{tabular}

When the mean values of the subscales shown in Table 1 are examined, it can be seen that the study participants perceived their training environments as more mastery-oriented and that the communication they had established with their coaches was based more on closeness compared with the other subscales.

Results of the Pearson Correlation Analysis showing the relationship between the volleyball players' scores on the Coach-Athlete Communication Relationship Questionnaire and Perceived Motivational Climate in Sport Scale subscale scores are presented in Table 4.

Table 2. Correlation analysis showing the relationship between sub-scales of the Coach-Athlete Relationship Questionnaire and Perceived Motivational Climate in Sport Scale

\begin{tabular}{|cl|c|c|c|c|c|}
\hline \multicolumn{2}{|l|}{ Sub-Dimensions } & $\mathbf{1}$ & $\mathbf{2}$ & $\mathbf{3}$ & $\mathbf{4}$ & $\mathbf{5}$ \\
\hline 1. & Closeness & 1 & & & & \\
\hline 2. & Commitment & $.73^{* *}$ & 1 & & & \\
\hline 3. & Complementarity & $.76^{* *}$ & $.70^{* *}$ & 1 & & \\
\hline 4. & Mastery-oriented & $.27^{* *}$ & $.33^{* *}$ & $.33^{* *}$ & 1 & \\
\hline 5. & Performance-oriented & -.17 & -.09 & -.21 & .03 & 1 \\
\hline
\end{tabular}

$$
* * \mathrm{p}<.01
$$

As shown in Table 2, no statistically significant relationship was found between the performance-oriented motivational climate sub-scale of the Perceived Motivational Climate in Sport Scale and the subscales of the Coach-Athlete Relationship Questionnaire. However, a statistically significant positive correlation was found between the mastery-oriented motivational climate subscale and all subscales of the Coach-Athlete Relationship Questionnaire. This finding indicates that perceptions of complementarity, closeness, and commitment are high in communication when the training environment is perceived as mastery-oriented.

Canonical correlation analysis was performed to determine whether there is a relationship between the sub-scales on the Coach-Athlete Relationship Questionnaire (SET 1) and the those of the Perceived Motivational Climate Scale (SET 2). For the canonical correlation analysis, SET $1(\mathrm{X})$ variables were defined as the subscales of the Coach-Athlete Relationship Questionnaire, and SET 2 (Y) variables were those of the Perceived Motivational Climate in Sport Scale. In the canonical correlation analysis to establish the relationship between SET 1 variables and SET 2 variables, and the Wilks's $\lambda$ test was used to determine whether the canonical model was statistically significant. The Wilks's statistical test confirmed that the canonical model was statistically significant (Wilk's $\lambda=.822, \mathrm{~F}_{(12,182.00)}=3.114, p<.005$ ).

In order to determine which of the canonical functions are significant, self-values and canonical correlation values for canonical functions need to be examined [43]. Two canonical functions were thus obtained as a result of canonical correlation analysis to determine the relationship between the coach-athlete relations data set (variable number $=3$ ) and the motivational climate data set (variable number $=2$ ). The eigenvalues and canonical correlation values for these functions are shown in Table 3.

Table 3. Eigenvalues and canonical correlation coefficients for canonical functions

\begin{tabular}{|c|c|c|c|}
\hline Function & Eigenvalue & $\begin{array}{c}\text { Canonical correlation } \\
\text { coefficient }\end{array}$ & $\begin{array}{c}\text { Canonical correlation } \\
\text { squared }\end{array}$ \\
\hline 1 & .153 & .365 & .13322 \\
\hline 2 & .054 & .227 & .05152 \\
\hline
\end{tabular}

As seen in Table 3, the correlation coefficient for the first canonical function is .365 . According to this finding, the coach-athlete relationship and motivational climate data sets account for $13.32 \%$ of variance in the first canonical function. In the second canonical correlation, the canonical correlation value, which was not taken into account in the first canonical function, and which shows the maximum association between the two canonical variables, can also be calculated. The resulting value for the second canonical function is .227 , indicating that the variance shared by the relationship data set and the motivational climate data set is $5.15 \%$.

The value that each variable describes in its set is expressed as the standardized canonical coefficient [42]. The standardized coefficients for the first set of variables 
are given in Table 4.

Table 4. Standardized correlation coefficients for variables in SET 1

\begin{tabular}{|c|c|c|}
\hline $\mathbf{X}$ Variables & $\begin{array}{c}\mathbf{1}^{\text {st }} \text { Canonical } \\
\text { coefficient }\end{array}$ & $\begin{array}{c}\mathbf{2}^{\text {nd }} \text { Canonical } \\
\text { coefficient }\end{array}$ \\
\hline $\mathrm{X} 1=$ Closeness & -.165 & -1.532 \\
\hline $\mathrm{X} 2=$ Commitment & -.573 & .126 \\
\hline $\mathrm{X} 3=$ Complementarity & -.359 & 1.338 \\
\hline
\end{tabular}

Examining the variables in Table 5 are in relation to the canonical function, the commitment variable is seen to contribute the most to the first canonical variable, while the closeness variable contributes the most to the second canonical variable. Standardized canonical coefficients for the variables in the second set are shown in Table 5.

Table 5. Standardized correlation coefficients for variables in SET 2

\begin{tabular}{|c|c|c|}
\hline Y Variables & $\begin{array}{c}\mathbf{1}^{\text {st }} \text { Canonical } \\
\text { coefficient }\end{array}$ & $\begin{array}{c}\mathbf{2}^{\text {st }} \text { Canonical } \\
\text { coefficient }\end{array}$ \\
\hline Y1= Mastery-Oriented & -.970 & .246 \\
\hline $\mathrm{Y} 2=$ Performance-Oriented & .274 & .962 \\
\hline
\end{tabular}

When the relationship between the variables in Table 5 and canonical function is examined, the mastery-oriented variable is found to have made the greatest contribution to the first canonical variable, while the performance-oriented variable made the greatest contribution to the second canonical variable.

\section{Discussion}

This study aimed to examine the relationship between coach-athlete communication and perceived motivational climate and found a correlation between coach-athlete communication and motivational climate variable sets (Table 2). Analysis of the canonical correlation show that the dimension of commitment of the Coach-Athlete Relationship Questionnaire and the dimension of mastery orientation of the Perceived Motivational Climate in Sport Scale made the greatest contributions to the first canonical function (Tables 4 and 5). These findings indicate that the coach-athlete relationship is related to the motivational climate created, and that the most influential factor in this relationship can be explained by commitment between the coach and athlete and the perception of a mastery-oriented motivational climate.

The Pearson Product-Moment Multiplication Correlation analysis was performed to determine the relationship between communication and the motivational climate scale subscales in this study. No significant association was found between coach-athlete relationship and performance-oriented motivational climate. However, a statistically significant and positive correlation was found between the mastery-oriented motivational climate subscale and the Coach-Athlete Relationship Questionnaire subscales of "complementarity", "closeness", and "commitment". This finding suggests that athletes with high scores in complementarity, closeness, and commitment perceive their training and competition environments as mastery-oriented.

The "complementarity" subscale of the Coach-Athlete Relationship Questionnaire describes an interactive process which develops a feeling of teamwork, mutual support, and cooperation [9], with the coach and athlete working together in a friendly, responsive, and willing manner to improve performance [44]. Therefore, the subscale of complementarity is expected to be associated with mastery-oriented motivational climate, the goal of which is effort, individual development, the contribution of each group member to the effort shown by the team, and the learning and development of new task by team members. The result of our study supported the first hypothesis. Similarly, the "commitment" subscale of the Coach-Athlete Relationship Questionnaire refers to showing unreciprocated commitment, the continuity of the relationship, the desire felt for the relationship, and positive intent. From this standpoint, when the motivational climate created by the coach is perceived to be mastery-oriented, when the athlete also fulfills his/her duties and strives to demonstrate personal development, he/she is expected to develop a perception that no problem will be experienced with the coach, and their commitment and positive relationship will continue. Therefore, a positive relationship between the commitment subscale of communication and mastery-oriented motivational climate also supports the first hypothesis proposed by our study. Another result obtained in this study is the positive correlation between the "closeness" subscale of the Coach-Athlete Relationship Questionnaire and mastery-oriented motivational climate. The closeness subscale is related to the emotional aspect of the coach-athlete relationship, and this component reflects the emotional depth of the relationship. Sarason et al. [45] stated that emotional closeness is an important factor in the athlete-coach relationship, and that the relationship between the athlete and the coach is of great importance for stability, and for continuing the establishment of a relationship on the basis of respect and trust. Thus, the finding that athletes who score high on the "closeness" subscale of the Coach-Athlete Relationship Questionnaire perceive their training environment as mastery-oriented supports the first hypothesis of this study.

The results of this study are consistent with those of previous studies $[35,46,47)$, although there are few studies examining the relationship between coach-athlete communication and the motivational climate created by the coach. Torregrosa et al. [47] found a positive correlation between the motivational climate created by the coach and the communication style of the coach, and this relationship positively predicted that the athlete would enjoy and be committed to the sport. Similarly, Kokkonen et al. [48] revealed that students who perceived their physical 
education teachers to be demonstrating democratic and socially supportive behaviors perceived the environment created as mastery-oriented. In addition, they reported that individuals who perceived the motivational climate as performance-ego based expressed that they received less social support and less democratic behavior from their instructors. In another study supporting our research findings, Nordin-Bates et al. [49] found a positive relationship between coach behaviors that support autonomy and the mastery-oriented motivational climate. They concluded that coaches who support cooperation, individual development, and effort, in other words coaches who create a mastery-oriented training environment, can contribute to the development of internal motivation in athletes. Similarly, Smith et al. [50] reported that athletes who had received positive and supportive feedback from their coaches following both successes and losses were more likely to perceive their training environments as mastery-oriented, whereas those who reported receiving less positive and more punitive feedback from their coaches perceived their training environments as more performance-oriented. As a result, athletes who perceive their training environment as mastery-oriented, in other words, those whose coaches emphasize cooperation, hard work, effort, support for teammates, and effort shown more than success or failure, will have more solid relationships with their coaches and will be closer to, more committed to, and more willing to work with them.

\section{Conclusions}

In light of findings revealing a positive relationship between "Coach-Athlete Communication" and "Mastery-Oriented Motivational Climate" as well as other research findings, it is advisable for coaches working with sports teams to create a mastery-oriented training environment. At the same time, creating quality milestones and environments to enhance sharing are recommended to increase positive relationships and effective communication between coaches and athletes. In this way, coaches make greater contributions to the athlete's enjoyment of training and improving their individual development. At the same time, enhancing positive relationship and spending quality time with athletes and creating mastery-oriented motivational climate may in turn increase athlete's intrinsic motivation and helps them to meet the demands of their positive emotions. The results of this study can help to the coaches to realize that the athletes will need assistance not only during participation in training, competitions but also at the outside of this environment (e.g. social life, school etc.). As known, high level sports where success is essential have some risk for athletes (e.g., intensive training that can lead to injury and burnout, de-selection that can lead to contract termination, school related problems). Therefore, coaches should develop close and supportive relationships to protect their athletes against such risks by taking all of the determinants mentioned above into consideration.

As with all research, this study has certain limitations. First, the study findings are based solely on the data obtained from athletes, i.e., no data was collected from coaches. Subsequent studies may recommend collecting data from both athletes and their coaches. This approach is important to provide more realistic information on the coach-athlete relationship. Secondly, the findings of this study were obtained only from 96 female volleyball players. Therefore, the population for which the results obtained can be generalized is rather limited. Incorporation of both male and female athletes who compete in other sports (both team and individual) in future studies is important for the findings to be generalizable. Third, this study is a cross-sectional study in the form of a relational screening. It may be advisable for future studies to be planned longitudinally and to thus yield information about how the coach-athlete relationship develops depending on the length of time they work together. Fourth, in this study we used PMCSQ to assess the perceived motivational climate of volleyball players. To sum, to collect more comprehensive data's PMCSQ-2 could adapt to Turkish players in the future studies.

\section{REFERENCES}

[1] Jowett S. Inter personal and structural features of Greek coach-athlete dyads performing in individual sports. Journal of Applied Sport Psychology, 18, 69-81, 2006.

[2] Jowett S., Clark-Carter D. Perceptions of empathic accuracy and assumed similarity in the coach-athlete relationship. British Journal of Social Psychology, 45, 617637, 2006.

[3] Jowett S., Ntoumanis N. The Coach-Athlete Relationship Questionnaire (CART-Q): Development initial validation. Scandinavian Journal of Medicine and Science in Sports, 14 (4), 245-257, 2004.

[4] Jowett, S., \& Shanmugam, V. Relational coaching in sport: It's psychological underpinnings and practical effectiveness. In R. Schinke, K. R. McGannon, \& B. Smith (Eds.), Routledge international handbook of sport psychology. London: Routledge. 2016.

[5] Rhind DJA., Jowett S. Relationship maintenance strategies in the coach-athlete relationship: the development of the COMPASS model. Journal of Applied Sport Psychology, 22, 106-121, 2010.

[6] Jowett, S., Meek G A. The coach athlete relationship in married couples: An explatory content analysis. The Sport Psychologist, 14, 157-175, 2000.

[7] Poczwardowski A., Barott JE., Henschen KP. The athlete and coach: Their relationship and its meaning: Results of an interpretative study. International Journal of Sport 
Psychology, 33, 116-140, 2002.

[8] Jowett S., Paull G., Pensgaard AM. Coach-athlete relationship. In J Taylor, GS Wilson; Applying Sport Psychology: Four Perspectives (pp. 153-170). Champaign, IL: Human Kinetics. 2005.

[9] Antonini-Philippe R., Seiler R. Closeness, co-orientation and complementarity in coach-athlete relationships: What male swimmers say about their male coaches. Psychology of Sport and Exercise, 7, 159-171, 2006.

[10] Jowett S. The coach-athlete partnership. The Psychologist, 18, 412-415, 2005.

[11] Jowett, S. Coaching effectiveness: The coach-athlete relationship at its heart. Current Opinion in Psychology, 16, 154-158, 2017.

[12] Fry MD., Gano-Overway LA. Exploring the contribution of the caring climate to the youth sport experience. Journal of Applied Sport Psychology, 22, 294-304. doi:10.1080/10413201003776352, 2010.

[13] Smith N., Quested E., Appleton PR., Duda JL. Observing the coach-created motivational environment across training and competition in youth sport. Journal of Sports Science, 35, 149-158. doi: 10.1080/02640414.2016.1159714, 2016.

[14] Mageau GA., Vallerand RJ. The coach-athlete relationship: A motivational model. Journal of Sports Science, 21, 883904. doi: 10.1080/ 0264041031000140374, 2003.

[15] Weiss MR., Amorose AJ., Wilko AM. Coaching behaviors, motivational climate and psycho-social outcomes among female adolescent athletes. Pediatric Exercise Science, 21, 475-492. doi: 10.1123/pes.21.4.475, 2009.

[16] Gould D., Collins K., Lauer L., Chung Y. Coaching life skills through football: A study of award winning high school coaches. Journal of Applied Sport Psychology, 19, 16-37. doi: 10.1080/10413200601113786. 2007.

[17] Smith RE., Smoll FL., Cumming SP. Effects of motivational climate intervention for coaches on young athletes' sport performance anxiety. Journal of Sport Exercise Psychology, 29, 39-59. doi: 10.1123/jsep.29.1.39, 2007.

[18] Aşçı FH., Kelecek S., Altıntaş A. The role of personality characteristics of athletes in coach-athlete relationships. Perceptual and Motor Skills Exercise and Sport, 121(2), 399-411, 2015.

[19] Hampson R., Jowett S. Effects of coach leadership and coach-athlete relationship on collective efficacy. Scandinavian Journal of Medicine and Science in Sports, 24, 454- 460, 2014.

[20] Jowett S., Lafreniere MK., Vallerand RJ. Passion for activities and relationship quality: a dyadic approach. Journal of Social and Personal Relationships, 30 (6), 734-749, 2013.

[21] Lorimer R, Jowett S. Empathic accuracy, meta-perspective, and satisfaction in the coach-athlete relationship. Journal of Applied Sport Psychology, 21, 201-212, 2009.

[22] Jowett, S., Adie, J. W., Bartholomew, K. J., Yang, S. X., Gustafsson, H., \& Lopez-Jimenez, A. Motivational processes in the coach-athlete relationship: A multicultural self-determination approach. Psychology of Sport and
Exercise, 32: 143-152, 2017.

[23] Adie, J. W., \& Jowett, S. Meta-perceptions of the coach-athlete relationship, achievement goals, and intrinsic motivation among sport participants. Journal of Applied Social Psychology, 40: 2750-2773, 2010.

[24] Duda JL., Whitehead J. Measurement of goal perspectives in the physical domain. In JL Duda (Ed.), Advances in Sport and Exercise Psychology Measurement. (pp. 21-48). Morgantown, WV: FIT, 1998.

[25] Xiang P., Couningham GB. Achievement goals, perceived motivational climate and their relation to students' satisfaction with physical activity. Research Quarterly for Sport and Exercise, 76: A96, 2005.

[26] Ames C. Achievement goals, motivational climate and motivational processes. In GC Roberts (Ed.), Motivation in Sport and Exercise (pp. 161-176). Champaign, IL: Human Kinetics. 1992.

[27] Ames C., Archer J. Achievement goals in the classroom: Students' learning strategies and motivation processes. Journal of Educational Psychology, 80: 60-267, 1998.

[28] Biddle S J H. Enhancing motivation in physical education. In G. C. Roberts (Ed.), Advances in Motivation in Sport and Exercise (pp. 101-127). Champaign, IL: Human Kinetics. 2001.

[29] Ntoumanis N., Biddle SJH. Affect and achievement goals in physical activity: A meta-analysis. Scandinavian Journal of Medicine and Science in Sports, 9, 315-332, 1999.

[30] Roberts GC., Ommundsen Y. Effect of goal orientation on achievement beliefs, cognition and strategies in team sport. Scandinavian Journal of Medicine and Sport, 6, 46-56, 1996.

[31] Newton, M., Duda, J. L., Yin, Z. N. Examination of the psychometric properties of the perceived motivational climate in sport questionnaire-2 in a sample of female athletes. Journal of Sports Sciences, 18, 275-290, 2000.

[32] .Ommundsen, Y., Roberts, G. C., Lemyre, P. N., \& Treasure, D. Perceived motivational climate in male youth soccer: Relations to socialemoral functioning, sportspersonship and team norm perceptions. Psychology of Sport and Exercise, 4: 397-413, 2003.

[33] Pensgaard AM., Roberts C. Elite athletes' experiences of the motivational climate: The coach matters. Scandinavian Journal of Medicine and Science in Sport, 12, 54-68, 2002.

[34] Balaguer I., Duda JL., Atienza FL., Mayo C. Situational and dispositional goals as predictors of perceptions of individual and team improvement, satisfaction and coach ratings among elite female handball teams. Psychology of Sport and Exercise, 3, 293-308, 2002.

[35] Olympiou A., Jowett S., Duda JL. The psychological interface between the coach-created motivational climate and the coach-athlete relationship in team sports. The Sport Psychologist, 22, 423-438, 2008.

[36] Karasar N. Bilimsel Araștırma Yöntemleri. Ankara: Nobel Yayın Dağıtım, 2009.

[37] Altıntaş A., Çetinkalp Z., Aşçı H. "Antrenör-Sporcu İlişkisinin Değerlendirilmesi: Geçerlik ve Güvenirlik Çalı̧̧ması”. Spor Bilimleri Dergisi, 23(3), 119-128, 2012. 
[38] Walling MD., Duda JL., Chi L. The Perceived Motivational Climate in Sport Questionnaire: Construct and Predictive Validity. Journal of Sport and Exercise Psychology, 15(2), 172-183, 1993

[39] Toros T. Elit ve Elit Olmayan Erkek Basketbolcularda Hedef Yönelimi, Güdüsel İklim ve Hedeflerin Özgünlük Güçlük Derecesi Özelliklerinin Yaşam Doyumuna Etkisi. Yüksek Lisans Tezi. Mersin Üniversitesi Sağlık Bilimleri Enstitüsü. 2001.

[40] Alpar R.Uygulamalı Çok Değişkenli İstatistiksel Yöntemler. Detay Yayıncilık, 2017.

[41] Kalaycı Ş. SPSS Uygulamalar: Çok değişkenli istatistik teknikleri. Ankara: Asil Yayın Dağıtım, 2009.

[42] Sümbüloğlu K., Akdağ B. İleri Biyoistatistiksel Yöntemler. Ankara: Hatipoğlu Yayınları, 2009.

[43] Sherry A., Henson RK. Conducting and interpreting canonical correlation analysis in personality research: A user-friendly primer. Journal of Personality Assessment, 84 (1), 37-48, 2005

[44] Jowett S., Timson-Katchis M. Social networks in sport: The influence of parents on the coach-athlete relationship. The Sport Psychologist, 19, 267-287, 2005.

[45] Sarason IG., Sarason BR., Pierce GR. Social support,

\footnotetext{
${ }^{\mathrm{i}}$ This study was presented as a poster paper at " 8 th National Sports Science Congress" which was conducted between 14-16 May 2015 at Mersin/Turkey and was awarded as the most successful poster presentation.
}

personality and performance. Journal of Applied Sport Psychology, 2, 117-127, 1990.

[46] Balaguer I, Crespo M, Duda JL. The relationship of motivational climate and athletes' goal orientation to perceived /preferred leadership style. Journal of Sport and Exercise Psychology, 18, 1996.

[47] Torregrosa M., Sousa C., Viladrich C., Villamarín F., Cruz J. El clima motivacional yel estilo de comunicación del entrenador como predictores del compromiso en futbolistasjóvenes. Psicothema, 2, 254- 259, 2008.

[48] Kokkonen JA., Kokkonen MT., Telama RK., Liukkonen JO. Teachers' behavior and pupils' achievement motivation as determinants of intended helping behavior in physical education. Scandinavian Journal of Educational Research, 57(2), 199-216. 2013

[49] Nordin-Bates E., Quested IJ., Walker E. Redding climate change in the dance studio: findings from the UK Centres for Advanced Training Sport, Exercise, and Performance Psychology. 10.1037/a0025316 Advance online publication, 2011.

[50] Smith SL., Fry MD., Ethington CA., Li Y. The Effect of Female Athletes' Perceptions of Their Coaches' Behaviors on Their Perceptions of the Motivational Climate. Journal of Applied Sport Psychology, 17: 170-177, 2005. 